\title{
Revisão de Protocolos de Acesso ao Meio em Redes Ad-Hoc Sem Fio
}

\author{
A Survey of Medium Access Control Protocols for \\ Wireless Ad Hoc Networks
}

Elvio J. Leonardo ${ }^{1}$; Ailton A. Shinoda ${ }^{2}$

Resumo

Protocolos de acesso ao meio para redes sem fio possuem várias características distintas daqueles utilizados em sistemas fixos. Em adição, para redes do tipo ad-hoc, as características do canal de rádio, as diversas tecnologias existentes para a camada física e as diferentes classes de serviços propostos para estes sistemas tornam complexa a tarefa de projetar algoritmos para disciplinar com eqüidade o acesso ao meio compartilhado que resultem eficientes, sensíveis ao consumo de energia e ao atraso imposto ao tráfego. Este artigo propõe-se a apresentar o corrente estado das pesquisas nesta área, incluindo propostas já disponíveis comercialmente assim como aquelas ainda em estudo.

Palavras chave: Rede sem fio. Rede ad-hoc. Protocolo MAC. Acesso ao meio.

\begin{abstract}
A number of issues distinguishes Medium Access Control (MAC) protocols for wireless networks from those used in wireline systems. In addition, for ad-hoc networks, the characteristics of the radio channel, the diverse physical-layer technologies available and the range of services envisioned make it a difficult task to design an algorithm to discipline the access to the shared medium that results efficient, fair, power consumption sensitive and delay bound. This article presents the current "state-of-art" in this area, including solutions already commercially available as well as those still in study.
\end{abstract}

Key words: Wireless network. Ad-hoc Network. MAC.

\section{Introdução}

Mecanismos de controle de acesso ao meio (Medium Access Control, MAC) para redes ad-hoc sem fio compõem uma área de pesquisa que tem despertado grande interesse ultimamente. As características do canal de rádio, as diversas tecnologias existentes para a camada física e as diferentes classes de serviços propostos para estes sistemas tornam complexa a tarefa de projetar algoritmos para disciplinar com eqüidade o acesso ao meio compartilhado que resultem eficientes, sensíveis ao consumo de energia e ao atraso imposto ao tráfego.

Várias características distinguem os protocolos de MAC sem fio daqueles utilizados em sistemas fixos (CHANDRA, GUMMALLA; LIMB, 2000), conforme descrito a seguir.

\footnotetext{
1 Univ. Est. de Londrina (UEL), Depto. Eng. Elétrica, 86055-900 Londrina PR, e-mail: elvio@uel.br.

2 Univ. Est. Paulista (UNESP), Fac. Eng. Elétrica, 15385-000 Ilha Solteira SP e-mail: shinoda@ dee.feis.unesp.br.
} 
Operação Half-Duplex. Devido à auto-interferência, isto é, a energia do transmissor que atinge o receptor colocado na mesma estação, em geral é muito dispendioso construir terminais capazes de receber e transmitir simultaneamente. Em conseqüência, a detecção de colisões durante a transmissão é uma qualidade não disponível e protocolos similares ao Ethernet não podem ser usados. Uma vez que colisões não podem ser detectadas, os protocolos de MAC sem fio procuram minimizar a probabilidade de colisões pelo uso de mecanismos direcionados à prevenção de colisões.

Canal Variante no Tempo. Nos canais com desvanecimento por multipercurso, o sinal recebido é a soma de cópias, atenuadas e deslocadas no tempo, do sinal transmitido. Com a mudança das características do canal e da posição relativa dos terminais, o envelope do sinal varia em função do tempo, podendo experimentar quedas severas na amplitude. Os terminais que desejarem estabelecer uma conexão devem testar o canal entre eles para avaliar a qualidade do enlace.

Erros de Rajada. Canais sem fio em geral apresentam uma taxa de erro mais elevada quando comparado aos canais fixos. Adicionalmente, os erros pudem vir em rajadas longas, quando o sinal se desvanece, resultando em uma probabilidade mais elevada da perda de pacote. Mecanismos de notificação de recebimento (acknowledgement) são em geral necessários para detectar a perda de pacotes e solicitar a retransmissão daqueles recebidos incorretamente.

\section{Detecção de Portadora Dependente da Posição.} Como o sinal transmitido se enfraquece com a distância, apenas os terminais até uma certa distância da antena do transmissor podem detectar a portadora. Isso pode causar o aparecimento dos problemas de terminais expostos e escondidos, conforme descrito a seguir. Estes problemas afetam negativamente a vazão do sistema.

Problema do Terminal Escondido. Dados os terminais A, B e C na Fig. 1. B está ao alcance dos sinais transmitidos por A e C mas estes estão fora do alcance um do outro. Se o terminal A estiver transmitindo para $\mathrm{B}$ e o terminal $\mathrm{C}$ deseja também transmitir para B, o terminal C incorretamente avaliará que o canal está livre uma vez que ele está fora do alcance de A, o terminal presentemente transmitindo. Se $\mathrm{C}$ começar transmitir, vai interferir com a recepção em B. Neste caso Cé denominado o terminal escondido para A. O problema do terminal escondido pode ser atenuado com o uso de um diálogo de "pedido para transmitir" (Request-to-Sent, RTS) e "permissão para transmitir" (Clear-to-Send, CTS), a ser explicado adiante, antes da transmissão dos dados.

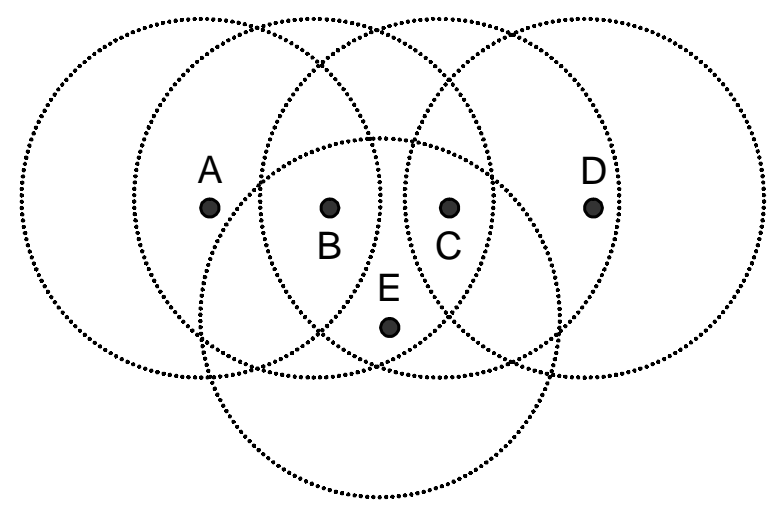

Figura 1. Influência da Posição no Monitoramento do Canal.

Problema do Terminal Exposto. Um terminal exposto é aquele que está ao alcance do transmissor mas fora do alcance do receptor. Na Fig. 1, se o terminal B estiver transmitindo para A e o terminal C verificar o canal ele avaliará que o canal está ocupado. Entretanto, uma vez que C está fora do alcance do terminal $\mathrm{A}$ ele não pode interferir com a comunicação corrente. Consequentemente $\mathrm{C}$ pode utilizar o canal para estabelecer uma ligação paralela com um outro terminal que se encontre fora do alcance de B, por exemplo, com o terminal D. Neste caso, $\mathrm{C}$ é denominado terminal exposto ao terminal B. Terminais expostos podem resultar na subutilização do canal. Este problema pode ser atenuado com o uso do diálogo de RTS/CTS.

Captura. O efeito de captura ocorre quando um terminal pode receber uma entre várias transmissões 
que estão ocorrendo simultaneamente se ela tiver uma intensidade muito maior do que as demais combinadas. Na Fig. 1, dados os terminais C e E, ambos ao alcance do terminal B. Se C e E estiverem transmitindo, a interferência pode resultar em uma colisão em B. Porém B pode receber com sucesso um dos sinais se um deles possuir uma intensidade muito mais elevada que o outro. O efeito da captura pode melhorar a vazão do sistema uma vez que o número de colisões diminui. Entretanto, ele favorece os terminais que estão mais próximos ao destinatário desejado e pode causar um uso do canal não eqüitativo.

Diálogo RTS/CTS. Muitos protocolos de MAC para redes ad-hoc usam variantes do diálogo RTS/CTS com o intuito de minimizar os problemas do terminal escondido e exposto. Neste diálogo, um terminal desejando transmitir dados primeiro verifica o estado do canal. Se o canal estiver livre por uma quantidade de tempo determinada, o terminal transmite um pacote de RTS. O terminal de destino ao receber o RTS responde com um pacote de CTS. Ao receber o CTS, o primeiro terminal entende que o canal foi adquirido e inicia a transmissão de dados. Todos os terminais (exceto os envolvidos no estabelecimento da comunicação) adiam qualquer tentativa de adquirir o canal ao ouvir o RTS ou o CTS.

Em função do exposto, fica claro que protocolos de MAC para redes ad-hoc exigem a consideração de um conjunto de parâmetros distinto daquele encontrado em sistemas fixos. Este artigo propõe-se a apresentar o corrente estado das pesquisas nesta área. A Seção classificação oferece uma lista explicativa dos parâmetros considerados relevantes para a definição destes protocolos. Protocolos existentes e propostos estão apresentados nas seções seguintes, com considerações finais colocadas na seção comentários

\section{Classificação}

Jurdak, Lopes e Baldi (2004), após análise de muitas das propostas disponíveis atualmente, oferecem um conjunto de características consideradas chaves na classificação dos protocolos de MAC para redes ad-hoc. Nesta compilação, são abordados aspectos como tipo de acesso, topologia, consumo de energia, iniciação da transmissão, tráfego e alcance, conforme colocado a seguir.

Separação e Acesso ao Canal. A maneira que o meio está organizado é importante no projeto de um protocolo. Por exemplo, cabe verificar se todas as estações compartilham um único canal que é utilizado tanto para controle como para dados, ou se o meio está dividido em diversos canais, em geral agrupados em canais de controle e canais de dados. Propostas mais antigas de protocolos de MAC tendiam para o uso de um canal único por causa da simplicidade. Entretanto, este arranjo é intrinsecamente sujeito a colisões e não tem um bom desempenho em condições de tráfego intenso. Particularmente com tráfego elevado, simulações mostram que os protocolos com canal único têm um número elevado de colisões de pacotes de controle, por exemplo, RTS e CTS, o que provoca aumento no tempo de back off ${ }^{3}$ mesmo quando o meio está inativo (TSENG; HSIEH, 2002). A escolha de canais múltiplos introduz a questão de como separá-los.

TDMA (Time Division Multiple Access): O acesso múltiplo por divisão de tempo divide o meio em pequenos intervalos de tempo de comprimento fixo, denominados slots. Um conjunto de slots forma um quadro e define a taxa da repetição dos slots. Por causa de sua natureza periódica, protocolos que utilizam TDMA são apropriados ao tráfego sensível ao atraso. Em TDMA, um terminal transmissor pode

\footnotetext{
3 Tempo de back off é o tempo, em geral aleatório, que o terminal deve aguardar antes de transmitir ou re-transmitir um pacote, por exemplo, quando o meio está ocupado.
} 
usar toda a banda disponível pela duração do slot a ele atribuído. Além disso, para acessar o meio no momento certo os terminais necessitam manter-se alinhados a slots e quadros e em conseqüência TDMA requer a sincronização entre terminais.

FDMA (Frequency Division Multiple Access): O acesso múltiplo por divisão de freqüência usa portadoras múltiplas para dividir o meio, permitindo que múltiplas transmissões ocorram simultaneamente, embora cada transmissor possa utilizar somente a largura de faixa atribuída à sua portadora.

CDMA (Code Division Multiple Access): O acesso múltiplo por divisão de código permite que os terminais transmissores utilizem toda a largura de faixa disponível o tempo todo. A cada transmissor é atribuído um dos diversos códigos ortogonais existentes. Transmissões que ocorrem simultaneamente são distinguidas uma das outras pelo código único utilizado no espalhamento espectral do sinal original. Uma exigência geral em CDMA é o controle da potência de transmissão. A razão para isto é que um sinal espúrio que seja muito mais forte do que o sinal desejado pode mascarar este último de maneira a impedir a sua recepção. Este fenômeno é conhecido como efeito próximo-distante (near-far).

O acesso múltiplo por divisão espacial (Space Division Multiple Access, SDMA), de maneira similar ao CDMA, permite que os terminais transmissores utilizem toda a largura de faixa disponível o tempo todo. Entretanto os terminais usam antenas direcionais e somente podem transmitir se o sentido de transmissão desejado não interfere com uma conversação correntemente em progresso.

Topologia. As redes ad-hoc têm um alto grau de flexibilidade e, em outras palavras, de incerteza. Os terminais podem ser móveis e tipicamente com capacidades e recursos distintos. A rede deve avaliar estes parâmetros e adaptar-se dinamicamente enquanto busca o melhor desempenho com o menor consumo de energia (JURDAK; LOPES; BALDI, 2004). A topologia de rede pode ser: centralizada, aglomerada, ou não-hierárquica (Fig. 2). A topologia centralizada tem um único terminal ou estação base que controla e gerencia a rede. O terminal central em geral é responsável por transmitir a todos informação relevante à operação da rede. Além disso, todos os outros terminais somente podem comunicarse através do terminal central. As topologias aglomeradas criam uma versão local de uma rede centralizada onde um terminal assume algumas ou todas as tarefas esperadas do terminal central. As topologias não-hierárquicas utilizam a abordagem de gerência distribuída onde todos os terminais estão no mesmo nível e o controle central é ausente. As topologias não-hierárquicas estão divididas em saltoúnico e saltos-múltiplos. No primeiro caso, supõese que o terminal de destino está ao alcance do sinal do terminal remetente. Na topologia com saltosmúltiplos o nó de destino pode estar fora do alcance direto do terminal originador. Neste caso, os terminais intermediários colocados entre fonte e destino são responsáveis por transmitir os pacotes até que eles alcancem o destino pretendido. Os protocolos com salto-único são mais simples mas acrescentam limitações ao tamanho da rede. Saltosmúltiplos permitem, ao custo de maior complexidade, que a rede cresça, dentro de certos limites, sem prejudicar o seu desempenho.

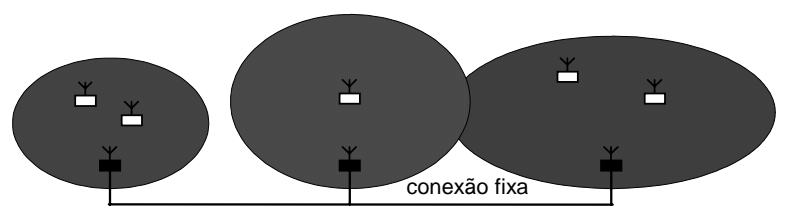

(a) Topologia centralizada.

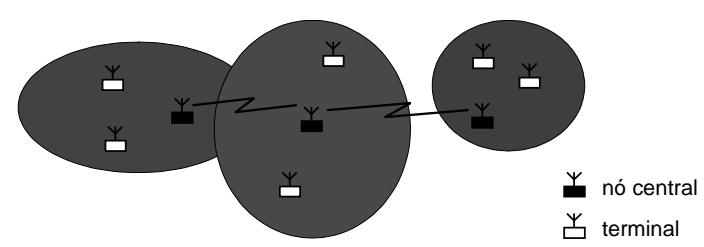

(b) Topologia aglomerada.

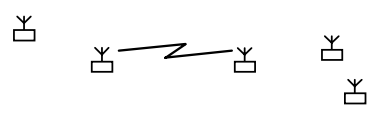

(c) Topologia não-hierarquica.

Figura 2. Exemplos de topologias de rede. 
Energia. O consumo de energia é uma questão relevante para todas as redes sem fio. A conservação de energia é particularmente importante para terminais móveis por causa do volume limitado de energia disponível nas baterias. Consequentemente, a maneira como o protocolo almeja a eficiência energética é uma característica importante. Uma estratégia eficiente para conservação de energia envolve diversos aspectos. A energia usada para transmitir o sinal representa uma grande parte grande do consumo. Idealmente a potência de transmissão utilizada deve ser apenas suficiente para alcançar o destino desejado.

Uma outra fonte de desperdício de energia é o tempo durante o qual os terminais permanecem monitorando o estado do canal ou ouvindo conversações irrelevantes. Se os terminais puderem antecipar os intervalos de tempo quando o meio estará indisponível eles podem decidir-se por permanecer em um modo de sonolência durante este período com o intuito de conservar energia. O comportamento da rede pode ser dinamicamente influenciado pelo nível de energia existente nos terminais. Esse fato se verifica, por exemplo, na seleção do nó central de um aglomerado de terminais ou na atribuição de prioridades de transmissão. Além disto, os terminais cientes de seu nível de energia podem em conseqüência ajustar o seu comportamento. A troca de mensagens do controle antes da fase da transmissão de dados representa também um desperdício de energia. Reduções nos gastos com controle devem portanto ser perseguidas.

Iniciação da Transmissão. Intuitivamente, esperase que o terminal que deseja começar uma conversação inicie a transmissão. E de fato a maioria dos protocolos está organizada desta maneira. Entretanto um protocolo "iniciado pelo receptor" pode ser mais apropriado em alguns casos, por exemplo, a uma rede de sensores. Em tais protocolos o receptor sonda seus vizinhos emitindo um pacote de "pedido para receber" (Request to Receive, RTR) que indique sua prontidão para receber dados. Se o receptor puder saber ou predizer com sucesso quando um vizinho lhe deseja transmitir dados, o uso desta informação leva, na verdade, a protocolos com maior desempenho. Porém para redes de uso geral e com tráfego de difícil predição, os protocolos "iniciados pelo transmissor" são ainda a melhor escolha.

Tráfego. Os protocolos são geralmente otimizados para o pior cenário previsto. Condições de baixo tráfego e distribuição esparsa de terminais não representam um desafio ao correto funcionamento das redes ad-hoc. Ao contrário, os protocolos são otimizados, dependendo do uso pretendido, para tráfego pesado, alta densidade de terminais e/ou para tráfego em tempo-real. Os protocolos que oferecem a possibilidade de reserva de canal são aqueles que apresentam melhor desempenho em situações de tráfego elevado e de tempo-real. Protocolos "iniciados pelo receptor" também possuem um bom desempenho em condições de tráfego elevado porque há uma probabilidade elevada de que os pacotes de RTR alcancem terminais desejando transmitir dados. Se a rede classificar terminais e tipos de tráfego pode, dessa maneira, atribuir prioridades baseadas na natureza do tráfego. Conseqüentemente pode oferecer encaminhamento preferencial ao tráfego em tempo-real. As redes densas tendem a sofrer interferência mais elevada devido a proximidade dos nós transmissores. Por essa razão, o uso de controle de potência pode representar uma diferença significativa no desempenho da rede.

Alcance. O alcance da transmissão é a distância da antena do transmissor em que a energia do sinal de rádio ainda permanece acima de um nível mínimo tolerável pelo receptor. Os protocolos podem ser classificados (JURDAK; LOPES; BALDI, 2004) como de alcance muito pequeno (escala até $10 \mathrm{~m}$ ), alcance pequeno (de 10 até $100 \mathrm{~m}$ ), alcance médio (de 100 até $1000 \mathrm{~m}$ ) e de longo alcance (acima de $1000 \mathrm{~m}$ ). Existe uma situação de custo-benefício entre o aumento do alcance de transmissão e a obtenção de uma capacidade espacial elevada. Em geral, essas decisões são negociadas durante o projeto do protocolo. 


\section{Protocolos Comerciais}

Nesta seção estão apresentados alguns dos protocolos atualmente disponíveis comercialmente, a saber: a família de padrões IEEE 802.11 e sua última extensão, o IEEE 802.11e, HIPERLAN $1 \mathrm{e}$ Bluetooth.

\section{IEEE 802.11}

A família de padrões IEEE 802.11 (IEEE 1999a, IEEE 1999b, IEEE 1999c) pode ser interpretada como uma versão sem fio do protocolo Ethernet para rede local (Local Area Network, LAN). O padrão 802.11a opera na faixa não-licensiada de $5 \mathrm{GHz}$ e oferece taxas de dados de até $54 \mathrm{Mb} / \mathrm{s}$. O comercialmente popular 802.11 b opera em $2.4 \mathrm{GHz}$, na faixa industrial, científica e médica (Industrial, Scientific, and Medical, ISM) e oferece taxas de dados de até $11 \mathrm{Mb} / \mathrm{s}$. As atividades correntes do grupo de trabalho 802.11 estão dirigidas para qualidade do serviço (Quality of Service, QoS) (802.11e, descrita mais tarde) e segurança (802.11i).

Os padrões 802.11 concentram-se na especificação das camadas de MAC e Física (Physical, PHY). Apesar de suas camadas PHY diferirem, os padrões 802.11 existentes utilizam os mesmos mecanismos de acesso ao meio. O mecanismo básico (e obrigatório) de acesso é denominado função de coordenação distribuída (Distributed Coordination Function, DCF). Um segundo (e opcional) mecanismo é a função de coordenação pontual (Point Coordination Function, PCF) onde um nó da central (o ponto de acesso ou access point) sonda os terminais de acordo com uma lista. DCF está disponível nas topologias ad-hoc e centralizada enquanto o PCF está disponível somente em configurações centralizadas. O protocolo de MAC oferece dois tipos de serviços de tráfego. $\mathrm{O}$ serviço assíncrono (obrigatório) é baseado no "melhor esforço" e é apropriado a serviços insensíveis ao atraso. O serviço com limite de tempo de entrega (opcional) é implementado usando PCF.
DCF usa um esquema de escute-antes-de-falar, baseado no mecanismo de acesso múltiplo com detecção de portadora (Carrier Sense Multiple Access, CSMA). Um terminal desejando transmitir um pacote de dados primeiro monitora o meio. Se o canal for detectado livre, o terminal espera um tempo de interquadro DCF (DCF Interframe Space, DIFS) (34 ms em 802.11a). Se o canal permanecer livre durante o período do DIFS, então o terminal começa a transmitir o seu pacote imediatamente após o fim do DIFS. A transmissão é concluída com sucesso quando o remetente recebe do destinatário um pacote de reconhecimento (Acknowledgement, ACK). Entretanto, se o canal for detectado ocupado um procedimento de prevenção de colisão é utilizado. Neste procedimento, após ter detectado que o canal está livre novamente por um período DIFS, o terminal que deseja transmitir ainda espera um tempo adicional que é calculado aleatoriamente (denominado tempo de back off, conforme definido anteriormente). $\mathrm{O}$ terminal então inicia a sua transmissão se o canal permanecer inativo durante este tempo adicional. O tempo de back off é um múltiplo do tempo de slot (9 ms em 802.11a) e é determinado individualmente e independentemente por cada terminal. Um número aleatório entre 0 e o valor "janela de disputa" (Contention Window, CW) é selecionado para cada nova tentativa de transmissão. O tempo de back off é somente decrementado durante o período em que o meio estiver na fase da disputa, mas, em caso contrário, permanece inalterado. Dessa maneira, o tempo de back off pode ser transferido por diversos ciclos de meio ocupado antes que se expire. Consulte a Fig. 3 para um exemplo do procedimento de back off. O valor inicial para CW é CWmin (15 em 802.11a) e como todos os terminais operam com o mesmo valor de CWmin todos têm a mesma prioridade média inicial de acesso. Após cada transmissão sem sucesso, isto é, aquelas em que o recebimento não é confirmado pelo receptor através de um ACK, o remetente dobra o valor de CW até um máximo definido por CWmax (1023 em 802.11a). Com um valor de CW maior a probabilidade de colisões diminui no caso de vários terminais tentando tomar o meio. 


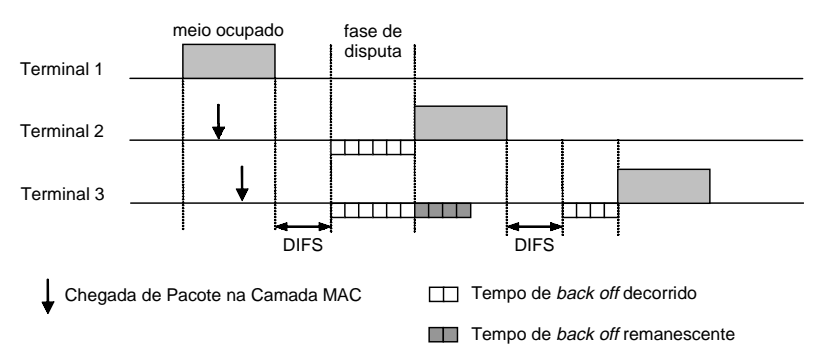

Figura 3. Mecanismo de tempo de back off.

Para reduzir o problema do terminal escondido, os protocolos 802.11 usam opcionalmente o diálogo de RTS/CTS. Os pacotes de RTS e CTS incluem a informação acerca do tempo pelo qual a transmissão de dados irá se prolongar, incluindo o envio do pacote de ACK. Os terminais que recebam ou um RTS ou um CTS usam esta informação para iniciar um temporizador, chamado de vetor de alocação de rede (Network Allocation Vector, NAV), que informa o período de tempo em que o meio estará indisponível.

Entre quadros de RTS e CTS consecutivos, ou entre quadros de dados e seu correspondente ACK, o espaço inter-quadro curto (Short Interframe Space, SIFS) (16 ms em 802.11) é utilizado. O valor do SIFS é menor que o do DIFS e, como consequiência, os terminais que necessitam transmitir estes quadros têm prioridade no acesso ao meio. A Fig. 4 ilustra uma conversação típica utilizando o IEEE 802.11.

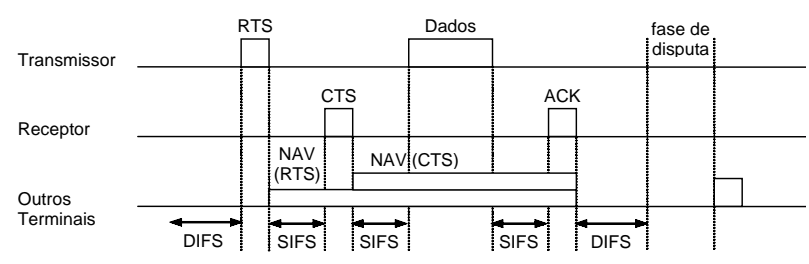

Figura 4. Conversação típica utilizando o IEEE 802.11.

\section{Hiperlan 1}

Rede local de alto desempenho tipo 1 (HIPERLAN 1) é um padrão de rede local sem fio que opera na faixa de $5 \mathrm{GHz}$ e oferece taxas de dados de até $23.5 \mathrm{Mb} / \mathrm{s}$ a usuários móveis nas topologias ad-hoc e centralizada. HIPERLAN 1 oferece serviço assíncrono do tipo "melhor esforço" e serviço com limite de tempo de entrega com prioridades hierárquicas. Existem 5 níveis de prioridade definidos, de 0 (mais elevado) a 4 (o mais baixo). A cada unidade de dado do protocolo (Protocol Data Unit, PDU) de MAC é atribuída uma prioridade que está proximamente relacionada ao seu tempo de vida residual normalizado (Normalised Residual Lifetime, NRL). O NRL é uma estimativa do tempo de vida que a PDU tem, considerando o número dos saltos que ainda restam a ela até chegar ao destino. Uma PDU é descartada se seu valor de NRL alcançar 0. HIPERLAN 1 designa alguns terminais como encaminhadores (fowarders) e estes são responsáveis por repassar os dados aos nós distantes em rede de saltos-múltiplos. Além disso, com o intuito de conservar energia, HIPERLAN 1 permite que os terminais "adormeçam". Estes terminais, chamados p-savers, informam aos terminais de suporte, denominados $p$-supporters, sobre os seus padrões de adormecido/despertado. Os p-supporters armazenam, então, os pacotes dirigidos aos terminais $p$-savers conforme a necessidade. Embora tenha algumas características interessantes, o HIPERLAN 1 não foi um sucesso comercial.

O mecanismo de acesso ao canal utilizado em HIPERLAN 1 é denominado acesso prioritário nãopreemptivo de eliminação-desistência (EliminationYield Non-Preemptive Priority Access, EY-NPMA). Ele compreende três fases: priorização (seleciona o pacote de dados com maior prioridade para transmissão), disputa (elimina todos os contendores exceto um) e transmissão. Durante a fase de priorização, o tempo é dividido em 5 sub-slots, numerados seqüencialmente de 0 a 4 . Um terminal desejando transmitir emite uma rajada (burst) durante o sub-slot correspondente à prioridade de sua PDU de MAC. Por exemplo, um terminal desejando transmitir uma PDU com prioridade 2 monitora o meio durante os sub-slots 0 e 1 . Se o meio permanecer livre durante estes sub-slots, o terminal então sinaliza a sua intenção transmitindo uma rajada durante o sub-slot 2. Caso contrário o terminal adia sua transmissão. 
Quando uma rajada é transmitida a fase de priorização termina, permanecendo na disputa somente os terminais que têm PDUs no mesmo nível de prioridade. Segue-se a fase de disputa. Ela começa com os terminais restantes transmitindo uma rajada de eliminação. O comprimento desta rajada varia entre 0 e 12 sub-slots e é selecionado pelos terminais aleatoriamente e independentemente um dos outros. Após ter transmitido a rajada, os terminais monitoram o meio. Se o meio estiver ocupado eles adiam as suas transmissões. Caso contrário, os terminais restantes selecionam aleatoriamente e independentemente um dos outros um valor entre 0 e 9 e começam monitorar o meio. Se, ao fim deste período, o meio continuar livre o terminal supõe que ganhou a disputa e então transmite os seus dados. Caso contrário ele adia a sua transmissão.

Está claro que o mecanismo não permite que nenhum pacote seja transmitido se houver outro com maior prioridade esperando. Ao mesmo tempo, o mecanismo não elimina totalmente a possibilidade de colisão mas consegue reduzi-la consideravelmente.

Similarmente ao IEEE 802.11, se o meio ficar inativo para um período maior que o período de interquadro, o terminal que deseja transmitir pode ignorar o mecanismo EY-NPMA e transmitir imediatamente.

\section{Bluetooth}

Bluetooth (1999) é um protocolo sem fio que usa a faixa não-licenciada conhecida como ISM para conectar dispositivos móveis e de mesa, tais como computadores e seus periféricos, dispositivos portáteis, telefones sem fio, telefones celulares, etc. O objetivo é produzir dispositivos de baixo custo, baixo consumo e baixo alcance, capazes de estabelecer enlaces de dados e voz a uma taxa bruta máxima de $1 \mathrm{Mb} / \mathrm{s}$. Bluetooth utiliza espalhamento espectral por saltos de freqüência (Frequency Hopping Spread Spectrum, FHSS) com 1600 saltos/ s. Para a voz, é utilizada uma ligação full-duplex de $64 \mathrm{~kb} / \mathrm{s}$ denominada conexão síncrona orientada (synchronous connection oriented, SCO). SCO designa um único slot periódico para uma conversação ponto-a-ponto. A transmissão de dados utiliza uma ligação assíncrona (asynchronous connection less, ACL) baseada no "melhor esforço" onde até 5 slots podem ser atribuídos. Em Bluetooth, os terminais estão organizados em pico-redes. Uma pico-rede contém um terminal identificado como mestre e até sete outros denominados escravos ativos. O mestre determina o padrão dos saltos do FHSS e os demais terminais necessitam sincronizar-se ao mestre da pico-rede. Um terminal, ao afiliar-se a uma pico-rede, recebe um endereço de membro ativo (Active Member Address, AMA), cujo comprimento é de 3 bits. Ele permanece então ou no estado transmite, quando ele está participando de uma conversação, ou no estado conectado. Bluetooth permite 3 estados de baixo consumo: estacionado (park), espera (hold) e interessado (sniff). Um terminal estacionado libera o seu AMA e recebe um endereço de terminal estacionado (Parked Member Address, PMA), cujo comprimento é de 8 bits. Os terminais nos estados espera ou interessado mantém o seu AMA, mas têm participação limitada na picorede. Por exemplo, um terminal no estado espera é incapaz de comunicar-se usando o modo ACL. Um terminal que não participa em nenhuma pico-rede está no estado alienado (stand-by). Pico-redes no Bluetooth podem coexistir no tempo e espaço e um terminal pode pertencer a diversas pico-redes. A formação de uma pico-rede começa quando seu futuro mestre inicia um processo de pesquisa, isto é, envia mensagens de inquisição (inquiry) com o intuito de encontrar outros terminais na vizinhança. Após ter recebido respostas da inquisição, o mestre pode explicitamente chamar os terminais para afiliarem-se à pico-rede. Se um mestre já souber a identidade de um outro terminal, pode pular a fase de pesquisa e chamar o terminal diretamente. Bluetooth usa o modo duplex por divisão de tempo (Time Division Duplex, TDD), onde mestre e o escravo alternam-se na vez de transmitir. Um escravo somente pode transmitir os dados após mestre ter acabado de transmitir para ele, isto é, os escravos transmitem somente se sondados pelo mestre. As 
transmissões podem durar um, três, ou cinco slots, embora somente a transmissão de slot único seja a única obrigatória.

\section{IEEE 802.11e}

O IEEE 802.11e é um protocolo emergente de MAC que adiciona à família de protocolos 802.11 um conjunto de características relacionadas à qualidade de serviço (QoS). Atualmente, há uma versão preliminar das especificações (IEEE, 2003). O alvo é servir melhor aplicações sensíveis ao atraso, tais como voz e multimídia.

No 802.11e, o acesso ao meio é denominado acesso melhorado ao canal distribuído (Enhanced Distributed Channel Access, EDCA). A fim de acomodar diferentes prioridades de tráfego, quatro categorias de acesso (Access Categories, AC) são introduzidas. A cada AC corresponde uma entidade de back off. As quatro entidades paralelas de back off encontradas em cada terminal 802.11e são denominadas (da maior para a menor prioridade): voz, vídeo, "melhor esforço" e "inferior".

Para efeito de comparação, os padrões existentes 802.11/a/b definem somente uma entidade de back off por terminal. Cada entidade de back off tem um conjunto distinto de parâmetros, tais como CWmin, Cwmax e o espaço inter-quadro de arbitragem (Arbitration Interframe Space, AIFS). AIFS é no mínimo igual a DIFS e pode ser ampliado se desejado.

Uma outra característica adicionada ao 802.11e é denominada de oportunidade de transmissão (Transmission Opportunity, TxOP). Uma TxOP define um intervalo de tempo que uma entidade de back off pode usar para transmitir dados. Ela é determinada por seu instante inicial e duração, e a duração máxima é dependente do AC. O protocolo define também a vida máxima de cada unidade de dados do MAC (MAC Service Data Unit, MSDU), que é também dependente do AC. Quando a vida máxima decorre o MSDU é descartado. Finalmente, o protocolo permite a notificação de recepção em bloco onde o recebimento de várias MSDUs consecutivas é reconhecido com um único quadro de ACK.

\section{Outros Protocolos}

Nesta seção são apresentados protocolos que, embora não tenham encontrado ainda uso comercial, apresentam aspectos inovadores e que buscam melhorar o desempenho em diversas condições.

PRMA (Packet Reservation Multiple Access): O acesso múltiplo com reserva de pacote (GOODMAN et al., 1989), permite que os terminais reservem um slot quando há dados periódicos a transmitir. PRMA supõe a existência de um nó central mas o mecanismo pode ser adaptado a outras topologias (JIANG et al., 2002). Em PRMA o meio é dividido em slots e um grupo de $N$ slots formam um quadro. Os slots estão reservados ou disponíveis. Os terminais disputam por slots disponíveis, transmitindo um pacote de dados. Para acessar o meio, eles usam o protocolo ALOHA. Na parte anterior do pacote há uma indicação da categoria do tráfego, se periódica ou esporádica. Uma vez que um pacote periódico é detectado com sucesso pelo nó central, o terminal supõe que o slot está reservado e pode ser usado sem disputa adicional. Quando o terminal cessar de transmitir os dados periódicos, o slot reservado fica então liberado.

MACA-BI (Multiple Access with Collision Avoidance By Invitation): O acesso múltiplo com prevenção de colisão por convite (TALUCCI et al., 1997), é um exemplo de um protocolo "iniciado pelo receptor". Em MACA-BI, o receptor sonda um candidato a remetente transmitindo um pacote de pedido de recepção (RTR). A fim de executar a sondagem de forma oportuna, o receptor deve predizer corretamente o tráfego originado pelo remetente. Esta tarefa é mais fácil quando o tráfego é periódico. Caso a fila de pacotes ou o atraso no terminal remetente cresça acima de determinados valores, a conversação poder ser iniciada por este pela transmissão de um pacote RTS. Melhorias ao 
MACA-BI são propostas em (GARCIA-LUNAACEVES; TZMALOUKAS, 1999). O acesso múltiplo iniciado pelo receptor com sondagem simples (Receiver Initiated Multiple Access with Simple Polling, RIMA-SP) e sondagem com duplo objetivo (RIMA with Dual-purpose Polling, RIMADP) são apresentados. Ambos os protocolos implementam o diálogo RTR/dados do MACA-BI. RIMA-DP dá uma finalidade adicional ao pacote de RTR: um pedido de transmissão feito pelo terminal enviando a sondagem. Após uma fase do reserva ambos os terminais podem trocar dados entre eles.

DBTMA (Dual Busy Tone Multiple Access): O acesso múltiplo com duplo tom de ocupado (HAAS; DENG, 2002) substitui o diálogo de RTS/CTS com os dois tons de ocupados fora da faixa: BTt (tom de ocupado da transmissão) e BTr (tom de ocupado da recepção). Quando um terminal tem dados para transmitir, ele primeiramente monitora a presença dos tons BTt e BTr. Se o meio estiver livre (nenhum tom de ocupado detectado), o terminal ativa o seu tom BTt, transmite um pacote RTS e desativa o BTt. Similarmente a outros protocolos, existe um tempo aleatório de back off se o meio estiver ocupado. O terminal de destino, ao receber um RTS, ativa o seu tom BTr e espera pelos dados. Quando o tom BTr é detectado, o remetente supõe que adquiriu o meio com sucesso. Após esperar um curto período (para o BTr se propagar) ele transmite o pacote de dados. Na recepção do pacote de dados com sucesso, o terminal de destino desativa o tom BTr, terminando a conversação. Se nenhum dado for recebido, o tom BTr é desativado pelo terminal de destino depois que um temporizador expira.

Fitzek et al. (2003), propõe um protocolo de MAC de saltos-múltiplos baseado no IEEE 802.11. Um canal comum transporta a sinalização, enquanto canais dedicados carregam o tráfego de dados e os pacotes de ACK Fig. 5 apresenta o diálogo de MAC proposto. O primeiro pacote de RTS é usado para contatar o destino e avaliar sua disponibilidade para receber dados. O remetente inclui uma lista de canais dedicados que estão desocupados e que é usada pelo terminal de destino para selecionar o canal a ser utilizado na conversação. Ele transmite então esta informação de volta ao remetente em um pacote de CTS. Se nenhum canal apropriado estiver disponível, o diálogo termina. Após ter recebido o pacote de CTS, o remetente transmite um pacote de prova (PROBE) pelo canal dedicado selecionado. O terminal de destino usa este pacote para testar as condições do canal. Ele transmite, então, um segundo pacote de CTS no canal comum que informa sobre o esquema de codificação/modulação escolhido. Um segundo pacote de RTS é transmitido pelo remetente para confirmar os parâmetros escolhidos. Embora com um custo maior em termos de complexidade, os autores reivindicam que o esquema proposto tem desempenho superior ao do 802.11 original.

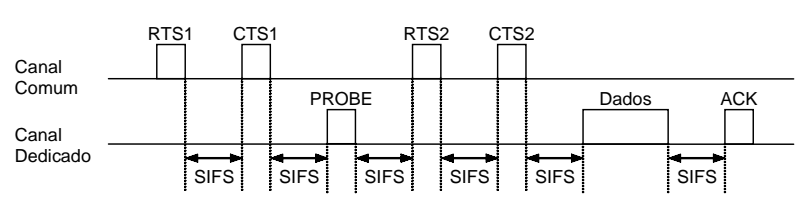

Figura 5. Diálogo de MAC proposto em Fitzek et al.(2003).

Chao, Sheu e Chou (2003), propõe um protocolo ciente do nível de tráfego e que comute entre mecanismos com disputa e livres de disputa, dependendo do volume do tráfego. Os mecanismos com disputa servem melhor para condições de tráfego leve, nas quais a probabilidade de colisão ao se tentar adquirir o meio é pequena. Em tráfego pesado, um mecanismo livre de disputa permite uma vazão mais alta e mais uniformemente distribuída. Em Chao, Sheu e Chou (2003) o mecanismo DCF do IEEE 802.11 é escolhido para os períodos com disputa enquanto que os períodos sem disputa utilizam um protocolo de passagem de bastão. O nível de tráfego é medido pelo atraso que os pacotes estão experimentando. É calculada por cada terminal para os pacotes que ele tem que transmitir. Durante um período com disputa, antes que um terminal transmita o seu pacote de dados, ele verifica o atraso do pacote que está a ponto de ser transmitido. Se o atraso é maior do que um valor predefinido $A$ o terminal cria um bastão e transmite-o com o pacote de dados. Isto indica a todos os terminais o começo de um período 
sem disputa. Uma vez que o atraso cai abaixo de outro valor predefinido $B$, o terminal em vias de transmitir remove o bastão. Isso indica o fim do período sem disputa e o começo de um novo período com disputa. O valor de $A$ é feito maior que o de $B$ para dar à decisão de comutação alguma histerese.

PCDC (Power Controlled Dual Channel): Canal duplo controlado por potência (MUQATTASH; KRUNZ, 2003) é um protocolo de saltos-múltiplos que visa manter a conectividade da rede utilizando a menor potência de transmissão possível. O PCDC utiliza o diálogo de RTS/CTS encontrado no IEEE 802.11 com algumas modificações. Cada terminal deve manter uma lista dos terminais vizinhos e a potência de transmissão necessária para alcançá-los. Quando um pacote é recebido, esta lista deve ser verificada. Se o remetente é desconhecido, os seus dados devem ser adicionados à lista. Caso contrário os seus dados devem ser atualizados. Em qualquer caso, o receptor necessita reavaliar a sua informação sobre conectividade e confirmar que conhece a maneira mais eficiente (no sentido de potência de transmissão) para alcançar todos os terminais que aparece em sua lista. Por exemplo, para alguns terminais pode ser mais eficaz utilizar um terminal intermediário em vez da rota direta. Em tráfego pesado, existe um número suficiente de pacotes circulando para manter os terminais informados sobre a vizinhança. Para períodos longos de inatividade, os terminais devem transmitir periodicamente um pacote de "alo" para manterem-se informados. O PCDC consegue eficiência espacial e simulações realizadas pelos autores indicam um aumento na vazão da rede.

Um protocolo de MAC de saltos-múltiplos e baseado em reserva que utiliza TDMA é apresentado em (FANG; KONDYLIS, 2003). O quadro TDMA está dividido em slots de dados e sinalização. Os slots de dados são marcados como: reservado para transmissão (RT), reservado para a recepção (RR), livre para a transmissão (FT), livre para a recepção (FR) ou livre para transmissão e recepção (FTR). O slot de sinalização é dividido em sub-slots, com cada sub-slot dividido em três partes: pedido, resposta e confirmação. Um terminal desejando transmitir envia um pacote de RTS. Neste pacote, o remetente informa a sua própria identidade, a identidade do receptor pretendido e os slots de dados que se deseja reservar. $\mathrm{O}$ receptor endereçado responde com um CTS se estiver com algum dos slots indicados em FR ou FTR, mas, em caso contrário permanece em silêncio. É possível que o pacote de CTS aceite a reserva de apenas um subconjunto dos slots pedidos. Terminais outros que o receptor endereçado respondem com um não-CTS (Not CTS, NCTS) se qualquer dos slots pretendidos estiver entre os seus RR. Qualquer terminal que detectar uma colisão de RTS também responde enviando um NCTS. Caso contrário permanece em silêncio. Finalmente, se o remetente receber com sucesso um CTS ele confirma a reserva enviando um pacote de confirmação (Confirm, CONF). Caso contrário ele permanece em silêncio. Os pacotes de RTS são transmitidos na parte de pedido do sub-slot; CTS e NCTS usam a parte de resposta; e os pacotes de CONF usam a parte de confirmação. Os slots de dados são divididos em três partes: baliza do receptor (Receiver Beacon, RB), dados e reconhecimento (ACK). Um terminal que tenha um slot de dados marcado como RR transmite um RB com a identidade do transmissor de dados ativo. Além disso, o receptor sinaliza a recepção correta dos dados pela transmissão de um ACK ao final do slot de dados. As simulações realizadas pelos autores indicam que o protocolo proposto tem desempenho superior ao IEEE 802.11 em tráfego entre moderado e pesado.

Fantacci, Ferri e Tarchi (2004), apresentam uma alternativa aos protocolos de MAC para redes $\mathrm{ad}$ hoc sem fio utilizando CDMA que procura minimizar os efeitos de engarrafamentos de tráfego. Na primeira tentativa de transmissão dos pacotes RTS/CTS, os terminais utilizam o menor fator de espalhamento definido, neste caso igual a 8. Sempre que o diálogo RTS/CTS falhar, o fator de espalhamento é multiplicado por dois e, após um período de back off, uma nova tentativa de transmissão é efetuada. Quando o máximo valor do fator de espalhamento é atingido, o terminal interrompe as suas tentativas de obter o canal e executa um segundo nível de mecanismo de back off. Observando-se que valores menores do fator de espalhamento permitem comunicação a taxas mais elevadas ao custo de maior interferência, enquanto valores maiores produzem 
o efeito contrário, os autores oferecem o esquema como um mecanismo de adaptação dinâmica da rede ao volume de tráfego exibido.

\section{Comentários}

Jurdak, Lopes e Baldi, (2004), fornecem um conjunto de características que um protocolo de MAC de uso geral para redes ad-hoc deve possuir. O uso de canais múltiplos para separar controle e dados é desejável e, dessa maneira, permite a redução da probabilidade de colisões. A necessidade de largura de faixa de canal flexível, de canais múltiplos e de eficiência espectral elevada sugerem que CDMA é a melhor escolha para a partição do canal. O protocolo que permita saltos-múltiplos é recomendado para assegurar o crescimento modular oferecido por topologias não-hierárquicas ou aglomeradas. A fim de favorecer o uso eficiente de energia, os protocolos necessitam controlar a potência de transmissão e permitirem modalidades de adormecimento. Finalmente, recomenda-se redes com alcance médio e com transmissão iniciada pelo remetente.

\section{Referências}

BLUETOOTH, Sig. Specification of the Bluetooth System, v. 1.0, 1999. Disponível em: <http:// www.bluetooth.org>. Acesso em: set. 2004.

CHANDRA, A.; GUMMALLA, V.; LIMB, J.O. Wireless Medium Access Control Protocols. IEEE Communications Surveys and Tutorials, v. 3, n. 2, 2000. Disponivel em: 〈http://www.comsoc.org/pubs/surveys〉. Acesso em : set. 2004.

CHAO, C.M.; SHEU, J.P.; CHOU, I-C. A load awareness medium access control protocol for wireless ad hoc network. IEEE International Conference on Communications, ICC'03, v. 1, p. 438-442, May 2003.

FANG, J.C.; KONDYLIS, G.D. A synchronous, reservation based medium access control protocol for multihop wireless networks. 2003 IEEE Wireless Communications and Networking, WCNC 2003, v. 2, p. 994-998, Mar 2003.

FANTACCI, R.; FERRI, A.; TARCHI, D. Medium Access Control Protocol for CDMA Ad Hoc Networks. IEEE Electronics Letters, v. 40, n. 18, p. 1131-1132, Sept. 2004.

FITZEK, F.H.P.; ANGELINI, D.; MAZZINI, G.; ZORZI, M. Design and performance of an enhanced IEEE 802.11 MAC protocol for multihop coverage extension. IEEE Wireless Communications, v. 10, n. 6, p. 30-39,Dec. 2003.
GARCIA-LUNA-ACEVES, J.J.; TZAMALOUKAS, A. Reversing the Collision-Avoidance Handhske in Wireless Networks. ACM/IEEE MobiCom'99, Aug. 1999, Seattle.

GOODMAN, D.J.; VALENZUELA, R.A.; GAYLIARD, K.T.; RAMAMURTHI, B. Packet reservation multiple access for local wireless communications. IEEE Transactions on Communications, v. 37, n. 8, p. 885-890, Aug. 1989.

HAAS, Z.J.; DENG, J. Dual busy tone multiple access (DBTMA) - a multiple access control scheme for ad hoc networks. IEEE Transactions on Communications, v. 50, n. 6, p. 975-985, June 2002.

IEEE 802.11 WG. Wireless LAN Medium Access Control (MAC) and Physical Layer (PHY) Specifications. IEEE/ ANSI Std. 802-11, 1999 edn (1999a).

IEEE 802.11 WG. Wireless LAN Medium Access Control (MAC) and Physical Layer (PHY) Specifications: highspeed physical layer in the $5 \mathrm{GHz}$ band. IEEE Std. 80211a (1999b).

IEEE 802.11 WG. Wireless LAN Medium Access Control (MAC) and Physical Layer (PHY) Specifications: higherspeed physical layer extension in the $2.4 \mathrm{GHz}$ band. IEEE Std. 802-11b (1999c).

IEEE 802.11 WG. Wireless LAN Medium Access Control (MAC) and Physical Layer (PHY) Specifications: Medium Access Control (MAC) Enhancements for Quality of Service (QoS). IEEE Draft Std. 802.11e/D5.0, Aug. 2003.

JIANG, S.; RAO, J.; HE, D.; LING, X.; KO, C.C. A simple distributed PRMA for MANETs. IEEE Transactions on Vehicular Technology, v. 51, n. 2, p. 293-305, Mar 2002.

JURDAK, R.; LOPES, C.V.; BALDI, P. A Survey, Classification and Comparative Analysis of Medium Access Control Protocols for Ad Hoc Networks. IEEE Communications Surveys and Tutorials. v. 6, n. 1, 2004. Disponivel em: <http://www.comsoc.org/pubs/surveys/>. Acesso em: 2004.

MUQATTASH, A.; KRUNZ, M. Power controlled dual channel (PCDC) medium access protocol for wireless ad hoc networks. In: ANNUAL JOINT CONFERENCE OF THE IEEE COMPUTER AND COMMUNICATIONS SOCIETIES, $22^{\text {nd }} ., 2003$, San Francisco. Proceedings... San Francisco, 2003. v. 1, p. 470-480.

TALUCCI, F.; GERLA, M.; FRATTA, L. MACA-BI (MACA By Invitation)-a receiver oriented access protocol for wireless multihop networks. In: IEEE INTERNATIONAL SYMPOSIUM ON PERSONAL, INDOOR AND MOBILE RADIO COMMUNICATIONS, $8^{\text {th }}$., 1997, Helsinki. Proceedings... Helsinki, PIMRC'97, 1997. v. 2, p. 435-439.

TSENG, Y.C.; HSIEH, T.Y. Fully power-aware and locationaware protocols for wireless multi-hop ad hoc networks. In: INTERNATIONAL CONFERENCE ON COMPUTER COMMUNICATIONS AND NETWORKS, $11^{\text {th }}$., 2002, Miami. Proceedings... Miami, 2002. p. 608-613. 